Research Article

\title{
Experimental Study on Flow Characteristics of Aeolian Sand in Fractures
}

\author{
Jiarui Chen $\mathbb{D}^{1},{ }^{1}$ Wenhu Gu $\mathbb{D}^{1},{ }^{1}$ Jihua Zhang $\mathbb{D},{ }^{1}$ Jitao Tang $\mathbb{D},{ }^{1,2}$ Zhengzheng Cao $\mathbb{D},^{3}$ \\ Jingke Wu $\mathbb{D},{ }^{1}$ Jianxiong Liu $\mathbb{D}^{1},{ }^{1}$ Weizhong $H e \mathbb{D}{ }^{1}$, and Fang Shi $\mathbb{D}^{4}$ \\ ${ }^{1}$ Faculty of Architecture and Civil Engineering, Huaiyin Institute of Technology, Huai'an, Jiangsu 223001, China \\ ${ }^{2}$ College of Civil Engineering, Nanjing Technology University, Nanjing 210009, China \\ ${ }^{3}$ International Joint Research Laboratory of Henan Province for Underground Space Development and Disaster Prevention, \\ Henan Polytechnic University, Jiaozuo 454003, China \\ ${ }^{4}$ Jiangsu Key Laboratory of Advanced Manufacturing Technology, Huaiyin Institute of Technology, Huai'an, Jiangsu 223003, \\ China
}

Correspondence should be addressed to Jihua Zhang; zhangjh84@hyit.edu.cn

Received 25 December 2020; Revised 9 January 2021; Accepted 25 January 2021; Published 15 February 2021

Academic Editor: Zhijie Wen

Copyright (c) 2021 Jiarui Chen et al. This is an open access article distributed under the Creative Commons Attribution License, which permits unrestricted use, distribution, and reproduction in any medium, provided the original work is properly cited.

It is one of the important safety problems in the process of mining shallow coal seams in western China that the rock mass affected by mining stress breaks and forms a penetrating fracture, leading to a sand burst in the working face. The self-developed test system is used to carry out the experimental study on the flow characteristics of Aeolian sand in fractures. The research work is focused on the influence of several parameters, such as the thickness of the Aeolian sand layer, the fracture opening, and the fracture dip angle on the velocity of sand particles in fractures. The results show the following: (1) The influence of fracture opening and fracture angle on sand burst rate is much greater than that of sand thickness. No matter what the fracture angle and fracture opening value are, the influence weight of sand thickness on sand burst rate is almost zero. (2) When other conditions are unchanged, with the increase of fracture dip angle, the sand burst rate increases significantly, and the relationship between the sand burst rate and the fracture dip angle is exponential. (3) The influence weight of fracture opening is the largest. With the increase of fracture opening, the sand burst rate increases logarithmically. Finally, according to the test results, the relation equation which can simultaneously describe the influence of fracture opening and fracture inclination on the rate of the sand burst is fitted. This study can provide a theoretical basis and scientific guidance for the prevention and control of coal mine sand inrush disasters caused by roof cracking in western coal mines.

\section{Introduction}

Located where Mu Us Desert borders the Loess Plateau, the Yulin mining area in northern Shaanxi Province, China, is covered by desert. During coal mining activities in this area, the thin bedrock will be fractured as a result of mining disturbance, and fracture channels will appear between the fractured rock blocks $[1,2]$ and will directly affect the stability of the overlying sand bed thus that the sand will partially break into the fracture even without water inrush, forming a giant funnel on the surface (Figure 1). For example, the sand inrush accident on the 1203 coal mining face in Daliuta Town [3] during the mining process caused the formation of an obconical funnel $24 \mathrm{~m}$ deep below the ground; the sand inrush on the 1931 coal mining face of the Henghe Coal Mine caused more than 5,000 square meters of sand to rush into the mine and 2 people trapped; the sand inrush accident in the Ciyaowan Coal Mine caused the collapse of 40,000 square meters roadways and the formation of a huge obconical funnel below the ground; a sand inrush on the 22402 coal mining face of the Halagou Coal Mine occurred on July 28,2010 , forming a funnel-shaped subsidence area with a diameter of $47 \mathrm{~m}$ and a depth of $12 \mathrm{~m}$ below the surface. On November 18, 2012, water burst and 


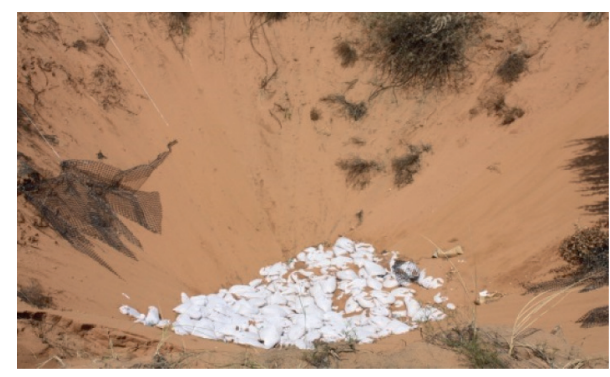

Figure 1: Collapse.

sand inrush happened to the Longde Coal Mine of China Huadian Corporation as a result of drilling for cables, causing the entire mine to flood [4].

The research on sand inrush disasters in coal mines is generally based on engineering geology. Recently, some scholars began to work on related research based on the theory of particle flow $[5,6]$. The granular state exists widely in our nature. After the French scientist Pierre put forward the concept of soft matter [7] in his Nobel Prize-winning speech in 1991, the concept of particulate matter being part of the soft matter was also brought forth accordingly.

The transport of particulate matter is another important aspect of the transport characteristics study of particulate matter [8]. The seepage of water in cohesionless soil will affect the flow of particles. The seepage force acting on the soil can reduce the equivalent gravity of soil particles, which in turn can also reduce the critical shear stress acting on the particles [9]. When the solid-liquid two-phase fluid moves in the pipeline, the collision and drag effect inside the particles counteracts the influence of the wall roughness on the distribution of average velocity. The introduction of particles will increase the Reynolds stress along the flow but will make the peak value of the Reynolds stress move to the higher normal position of the wall [10]. When flowing in the channel, the water and sand fluid will produce an erosion effect on the pipeline, whose effect will be enlarged with the increase of the bending angle of the seepage channel [11]. When coarse, medium, and fine sands flow in narrow and wide fractures, the contact and interaction between particles and between particle walls will influence the flow of slurry, whose influence will become stronger with the increase of particle concentration [12]. Sheng et al. [13, 14] proposed a calculation method that can describe the transport and separation characteristics of sand particles of various sizes in a fluidized bed. Ancey Heyman [15] established a model framework for studying the random fluctuation of bed load movement, which framework considers the random fluctuation of not only the number of moving particles but also the particle velocity. Li-Mo, Xing-Kui[16] studied the singlestep movement of bed load particles under six different water-sediment conditions and made a statistical analysis on the movement law of a large number of particles. Hadeler [17] offered a model of flow, sedimentation, and static layers formed on particle surface to explain the time-varying process of particle movement. Sun et al. [18] studied the movement law of solid particles by analyzing the characteristics of the internal state and structure of particles.
The flow characteristics of Aeolian sand in fractures and fissures are the key factor in the prevention and control of sand inrush disasters in coal mines. The relevant research usually draws on the experience of the eastern mining area $[19,20]$ and simply analyzes the geological conditions $[21,22]$ of sand inrush accidents. Few research has been done on sand rush disasters on the basis of the sand inrush mechanism. This paper uses the self-developed fracture sand inrush test device to study the flow law of Aeolian sand in fractures with a certain degree of opening and inclination and obtain the relationship between the sand inrush velocity and the fracture opening and inclination. This paper puts forward and establishes a calculation model that can simultaneously describe the influence of fracture inclination and opening on the sand inrush velocity, providing a reference for the prevention and control of sand inrush disasters in the western mining area.

\section{Engineering Geological Conditions and Generalized Model of Fracture Sand Inrush}

2.1. Engineering Geological Conditions. The area studied by this paper is located in the mining areas in Yuyang District, Shenmu County, and Fugu County of Yulin City in the north of Shaanxi Province (hereinafter referred to as the "Mining Areas"). The Mining Areas are generally border areas between Mu Us Desert and Loess Plateau. Due to the fact that northern Shaanxi is located in the inland, coupled with the lack of water resources, drought for many years, and low survival rate of vegetation, most of the surface of the mining area is covered by desert. The overlying strata of the mining area are shown in Table 1.

The surface of the mining area is covered by Quaternary loose sediments, especially Aeolian sand, with bedrock extruding from only a few gullies. The mining area, simple in both structure and sequence, has been developed into horizontal bedding. The strata from Mesozoic to Cenozoic are Yongping formation of Triassic, Yan'an formation of the middle and lower Jurassic, and Zhiluo formation and quaternary system of the middle Jurassic.

The whole mining area is covered with Quaternary Aeolian sand, while the Quaternary unconsolidated formation exists sporadically in some areas, most of which lies under the Aeolian sand. As the strata are composed of loose particles and almost have no strength, their basic quality stands at grade $\mathrm{V}$. Weathered rock of Zhiluo formation refers to the rock stratum of a certain thickness at the top of the bedrock. After weathering, the rock is extremely soft with very low saturated uniaxial compressive strength, and the rock structure is seriously damaged. Yan'an formation roof sandstone: it is mainly composed of medium and finegrained sandstone, with coarse grains in some areas and a saturated uniaxial compressive strength of $26 \mathrm{MPa}$. It is a relatively soft coal seam roof with a relatively complete rock mass structure.

2.2. Fracture Sand Inrush Model. The coal seam in the 22404 fully mechanized coal mining face of Halagou coal mine is 
TABLE 1: Characteristics of borehole rock strata at the sand breaking point of Halagou Mine.

\begin{tabular}{lcc}
\hline Stratum & $\begin{array}{c}\text { Strata thickness } \\
(\mathrm{m})\end{array}$ & Rock composition \\
\hline Quaternary & 50.31 & Aeolian sand \\
\hline $\begin{array}{l}\text { Straight from } \\
\text { group }\end{array}$ & 24.63 & $\begin{array}{c}\text { Siltstone, fine } \\
\text { sandstone }\end{array}$ \\
\hline & 10.32 & Interbedded fine sand \\
& 16.74 & $\begin{array}{c}\text { Medium fine sandstone } \\
\text { Yan'an group }\end{array}$ \\
& 7.00 & $\begin{array}{c}\text { Siltstone, fine } \\
\text { sandstone } \\
\end{array}$ \\
& 5.40 & Coal seam \\
& 3.49 & Siltstone \\
\hline
\end{tabular}

$5.54 \mathrm{~m}$ in thickness and $5.2 \mathrm{~m}$ in designed mining height. The coal mining face is covered with $29.5-70 \mathrm{~m}$ thick bedrock, with the thinnest bedrock located at the open-off cut. On top of the bedrock is the $20-60 \mathrm{~m}$ thick Aeolian sand of unconsolidated formation. When the coal mining face was pushed forward for $38 \mathrm{~m}$, No. 92 hydraulic support point suffered sand inrush and was expanding rapidly. As a result, a circular funnel-shaped collapse area with a diameter of $47 \mathrm{~m}$ and a depth of $12 \mathrm{~m}$ was formed at the mining face air return way $50 \mathrm{~m}$ away from the surface corresponding to the sand inrush point. The occurrence of sand inrush is related to many factors, such as the scale and nature of the overlying aquifer, the thickness of the coal seam, the mining method, and the thickness, strength, and destructional form of the overlying rock [21]. Based on the investigation of the geological conditions of the Yushenfu study area and the specific engineering geological conditions of the western coal fields such as the Halagou coal mine and Xiaojihan coal mine, it can be judged that this sand inrush disaster is a typical sand inrush in the caving zone.

The sand inrush passage is a bond connecting the upper unconsolidated formation to the coal mining face. In the study area, the coal seam is shallow and the overlying strata thin. The bedrock of 22402 coal mining face in the Sipan zone of Halagou coal mine is $29.5-70 \mathrm{~m}$ thick, and the bedrock of 1203 fully mechanized coal mining face in Daliuta coal mine is only $20 \mathrm{~m}$ thick. In addition, the silty fine rock of Zhiluo formation in northern Shaanxi Province is fragile after weathering, and the rock is extremely inferior in quality and the rock mass poor in integrity. The highintensity mining has led to the destruction of the overlying bedrock, the collapse of overlying strata, and the formation of falling cracks or collapse zone gaps, and the cracks on the broken rock mass have penetrated the unconsolidated formation and the downhole coal mining face. Production practice demonstrates that in the mining process, the thin bedrock and shallow coal seam in northern Shaanxi Province will show violent mine pressure and is easy to cause falling and collapse damage, the fracture is directly connected to the Quaternary unconsolidated formation, and on the surface appears steps and other subsidence phenomena.

In the coal mining process, when the fractures caused by mining activities or other natural channels affect the overlying unconsolidated formation, weakly cemented particles such as Aeolian sand will pass through the fracture channel and inrush into the underground coal mining face under the action of gravity through the sand inrush channel, leading to the sand inrush disaster, as shown in Figure 2.

\section{Generalized Model and Test Principle of the Test System}

3.1. Fracture Sand Inrush Test System. The final design scheme of the fracture sand inrush characteristics test system has been developed by determining the function of the test system, taking into consideration the various factors in the fracture sand inrush test, and through comprehensive analysis and assessment. The test equipment is mainly composed of natural Wind-Blown Sand in the western mining area, sand container, container support, fracture simulation equipment, and real-time recording equipment (see Figure 3).

3.1.1. Test Support System. The self-developed fracture sand inrush test system can be used to study the influence of fracture opening, fracture angle, sand layer thickness, and other factors on fracture sand inrush characteristics. The sand inrush sleeve and weight are designed to simulate the Aeolian sand layer of different thickness. Thread is processed at the bottom of the sleeve to facilitate the connection between the sleeve and the fracture specimen. A movable partition is designed at the joint of the specimen and the sleeve to prevent the sand grains from collapsing.

3.1.2. Piston and Compression System. Due to the size limitation of indoor test equipment, it is difficult to directly produce equipment tens of meters high to simulate the sand bed. The piston and weight are designed to increase the pressure of the test sand bed in order to simulate the thicker sand bed. The thickness of the sand bed is estimated using the following formula:

$$
h=\frac{m}{\rho A},
$$

where $h$ is the thickness of sand bed; $m$ is the weight of weight and piston; $\rho$ is the density of Aeolian sand; $A$ is the area of where the piston contacts the Aeolian sand.

To prevent the friction between the piston and the sleeve wall from affecting the accuracy of the test, the diameter of the piston is designed to be slightly smaller than that of the sleeve. Both the upper and lower parts of the piston are processed into planes, and the two planes are parallel and perpendicular to the piston rod. The lower plane of the piston can exert even pressure on the sand grains.

3.1.3. Sand Grain Materials. All sand grains used are natural Aeolian sand collected from Erdos (Figure 4). The size of sand grains ranges from $0.074 \mathrm{~mm}$ to $0.25 \mathrm{~mm}$, the density of Aeolian sand in a natural loose state is about $1.426 \mathrm{~g} / \mathrm{cm}^{3}$, and the friction angle of Aeolian sand is $31.3^{\circ}$. 


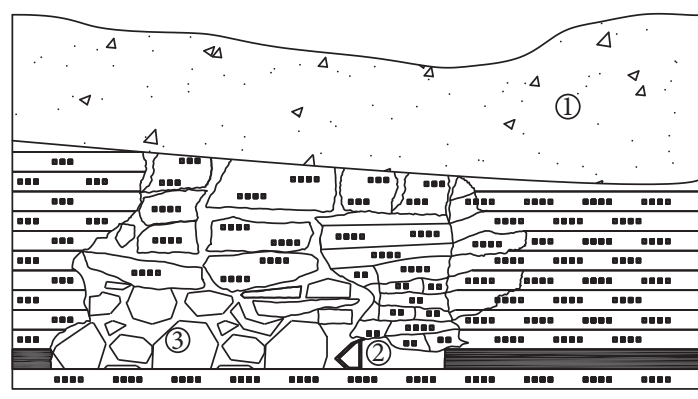

(1) Aeolian sand

(2) Stope

(3) Collapse zone and shear fracture

FIGURE 2: Fracture sand inrush model.

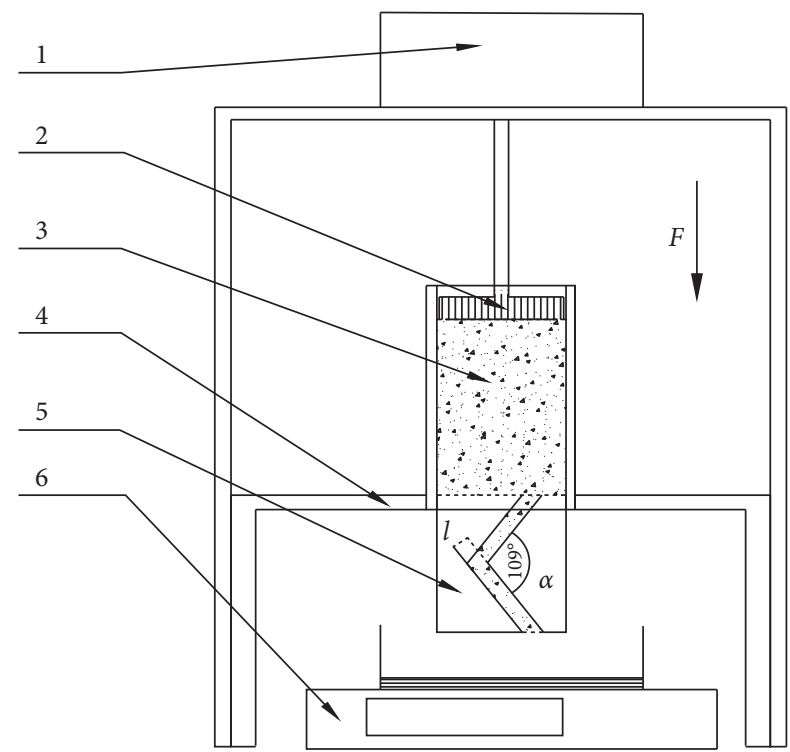

Figure 3: Fracture sand inrush test system. (1) Loading system; (2) piston; (3) sand grain; (4) test support; (5) fracture specimen; (6) data acquisition system.

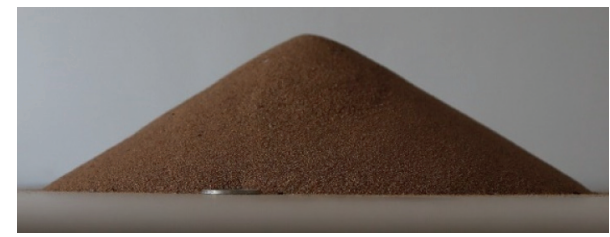

FIgURE 4: Aeolian sand in the western mining area.

3.1.4. Fracture Specimen. In order to study the characteristics of fracture sand inrush by way of test, it is necessary to process a fracture specimen with specific fracture width and angle, which requires a kind of material that is easy to process and has stable properties. To meet this requirement, the specimen is made of plexiglass, and the fracture is roughly processed.
The flow of sand grains in fracture should meet two requirements: first, the inclination of the fracture should be higher than the friction angle of Aeolian sand; second, the opening of the fracture should be larger than the maximum grain size of Aeolian sand. The distribution of the angles and openings of the mining-induced fracture of the overlying strata is complex. Taking into consideration the engineering environment and the test scheme, it is determined that the fracture angles $\alpha$ are 45, 55, 65, and 90 degrees, respectively. Considering the distribution of Aeolian sand by particle size and referring to the fracture seepage law "Cubic Law," it is determined that the fracture openings $l$ are 2, 3, 4, 5, and $6 \mathrm{~mm}$, respectively. In order to reduce the influence of the boundary effect on the test results, the length of the fracture of the specimen processed should be less than the diameter of the specimen. The length of the fracture of the specimen is $30 \mathrm{~mm}$, and the height $h$ is $100 \mathrm{~mm}$, as shown in Figure 2. The fracture is numbered in the form of $l-\alpha$. For example, "specimen 2-90" indicates a fracture specimen with a $2 \mathrm{~mm}$ fracture opening and a $90^{\circ}$ fracture inclination (Figure 5).

3.1.5. Fracture Sand Inrush Velocity Measurement System. The measurement system is located at the lower part of the support where the sand grains break into the weighing equipment through the fracture, and the weighing system will record the curve of the relationship between the sand inrush amount and time in real time.

3.2. Fracture Sand Inrush Test Process. The whole test process can be divided into the following steps: test system debugging, assembling of different fracture specimens, filling of sand sleeve, zeroing of weighing instrument, and initialization of software recording system. The whole test process is shown in Figure 6.

(1) Test system debugging: assemble and debug the test system.

(2) Filling of sand sleeve: weigh a certain amount of sand and put it in the sand sleeve.

(3) Zeroing of weighing instrument: before the test starts, put the sand collection container on the electronic weighing scale, and reset the display digits of the electronic weighing scale to zero for the convenience of sand weighing and data collection.

(4) Initialization of software recording system: turn on the data recording software, connect it with the electronic weighing scale system, and put it in the data recording state.

(5) Start the test: open the movable partition and start the test.

After completion of one test, the test data recorded by the software should be saved and the test device cleaned up for proceeding with the next round of test. To ensure the accuracy of the test data, each round of test is repeated many times until there are more than three groups of similar data. 


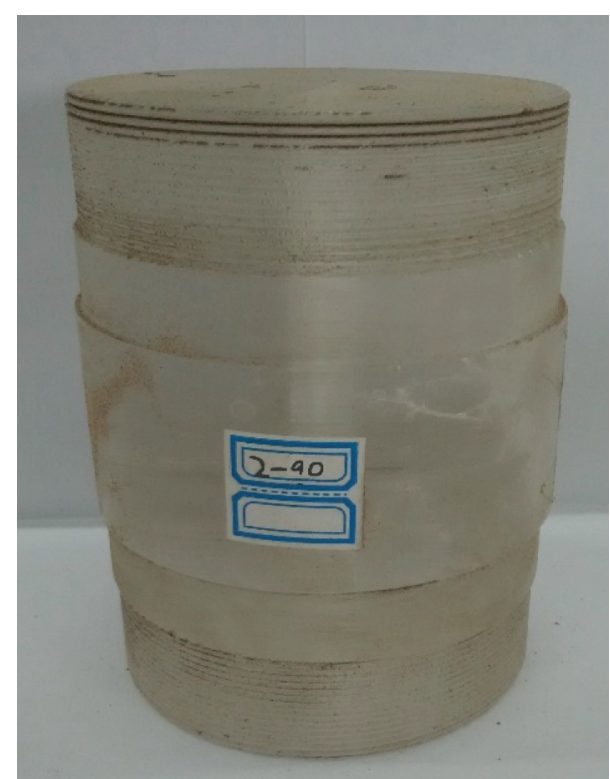

FIGURE 5: Fracture specimen model (2-90).

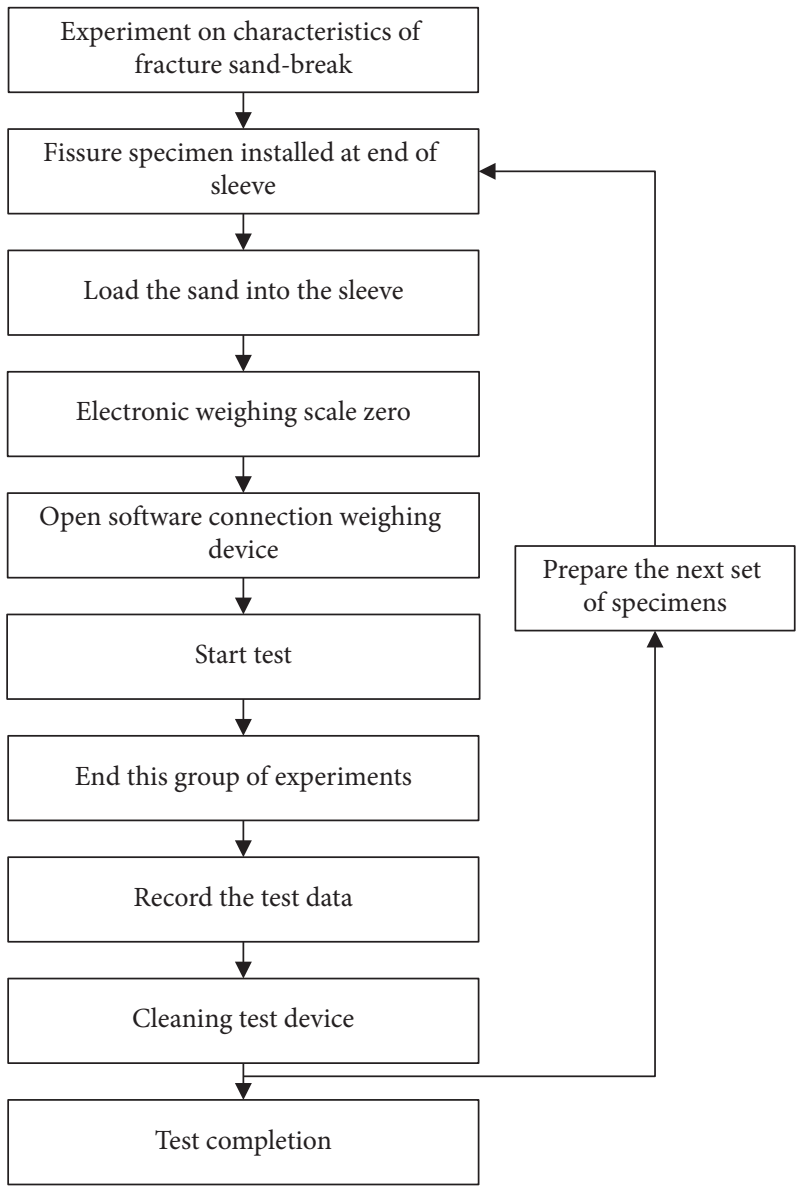

Figure 6: Flow process diagram of fracture sand inrush.

\section{Analysis of Fracture Sand Inrush Results}

4.1. Time-Mass Characteristics of Fracture Sand Inrush. During the sand inrush process of the test, the mass and time of sand inrush increase in a linear manner. It can be considered that in a group of tests, the velocity of sand inrush is constant if the specimen has a specific fracture opening and angle. Figure 7 shows the natural sand inrush curves of several groups of specimens in fracture sand inrush test.

It is found through analysis of the fracture sand inrush test results that the sand grains fall at a constant speed (Figure 7), which has a certain impact on the container, so the data on the electronic scale should be taken into account during the assessment of the test results.

The reading on the electronic weighing scale is $m_{\mathrm{b}}$, and the value is the sum of the sand mass and the sand impact mass on the electronic weighing scale.

$$
m_{b}(t)=m_{s}(t)+\frac{F_{s f}}{g} .
$$

where $m_{\mathrm{b}}(t)$ is the reading on the electronic weighing scale, $m_{\mathrm{s}}(t)$ is the mass of sand grains on the electronic weighing scale, $F_{s f}$ is the impact of sand on the scale, and $g$ is the gravitational acceleration.

The actual mass of sand grains on the electronic weighing scale at a certain time $t$ is as follows:

$$
m_{s}(t)=m_{b}(t)-\frac{F_{s f}}{g} .
$$

The velocity of the sand inrush of the fracture specimen is as follows:

$$
\frac{\mathrm{d} m_{s}(t)}{\mathrm{d} t}=\frac{\mathrm{d} m_{b}(t)}{\mathrm{d} t}-\frac{1}{g} \frac{\mathrm{d} F_{s f}}{\mathrm{~d} t},
$$

$m_{\mathrm{b}}(t)$ and $m_{\mathrm{s}}(t)$ are functions of time $t$ because the falling velocity of grains is constant, and the impact force $F_{\text {sf }}$ is only related to the falling velocity of sand grains, not to time $t$. Therefore, it can be concluded that

$$
\frac{\mathrm{d} m_{s}(t)}{\mathrm{d} t}=\frac{\mathrm{d} m_{b}(t)}{\mathrm{d} t}
$$

\subsection{Influence of Sand Bed Thickness on Fracture Sand Inrush} Characteristics. For the purpose of this paper, a simulation stress environment is used to simulate the sand beds of different thicknesses.

Based on the measurement of the natural Aeolian sand collected in the Ordos in the western mining area, the density of Aeolian sand in the natural state is about $1.426 \mathrm{~g} /$ $\mathrm{cm}^{3}$. The weights applied on the sleeve sand body are 0 , $2.894,5.462,8.802$, and $11.369 \mathrm{~kg}$, respectively. The diameter of the piston is $70 \mathrm{~mm}$. Through calculation according to formula (1), the simulated extra sand thickness is $0,0.527$, $0.996,1.600$, and $2.073 \mathrm{~m}$, respectively. To make it simple, the above five thicknesses are indicated with s1, s2, s3, s4, and s5, respectively. Each round of test is repeated many times.

As the thickness of the sand bed increases, the pressure on the sand grains on top of the fracture becomes larger. Figure 8 shows the curve of the relationship between the thickness of the sand bed and the velocity of sand inrush. 


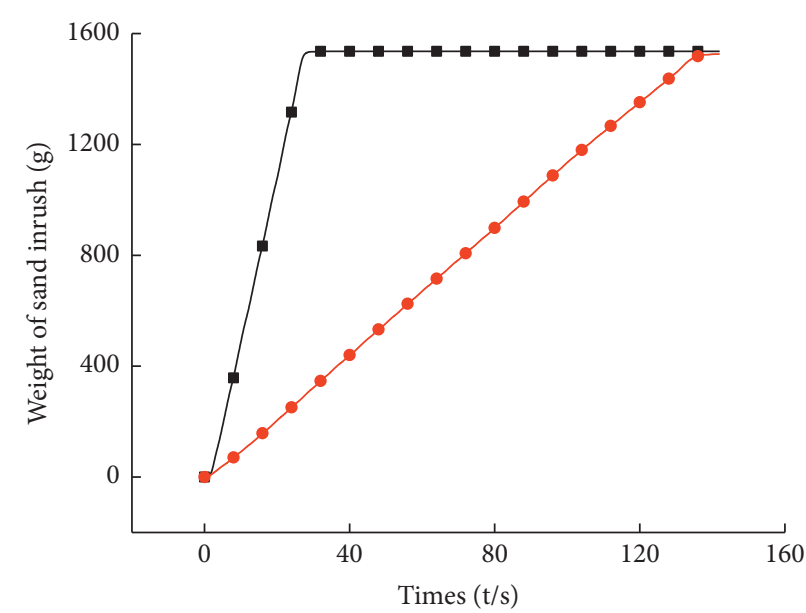

-- Test specimen (6-90)

- Test specimen (2-90)

Figure 7: The curves of the specimen of sand inrush.
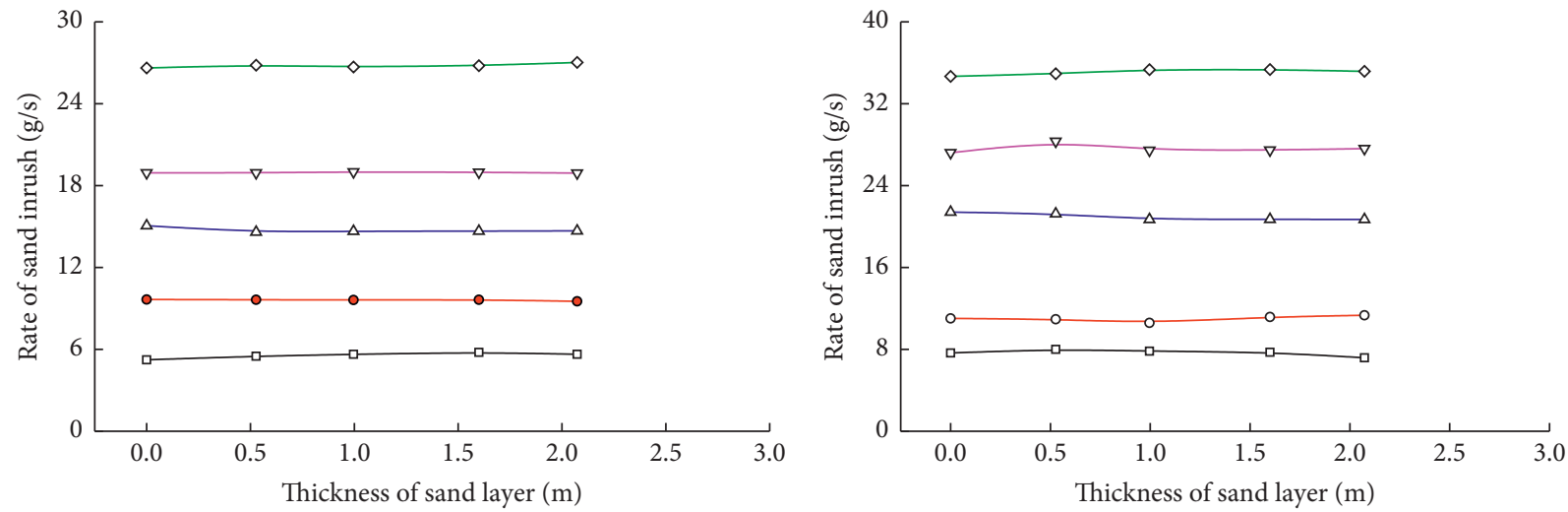

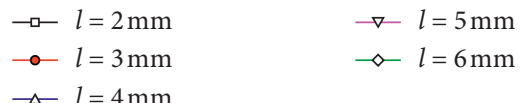

(a)

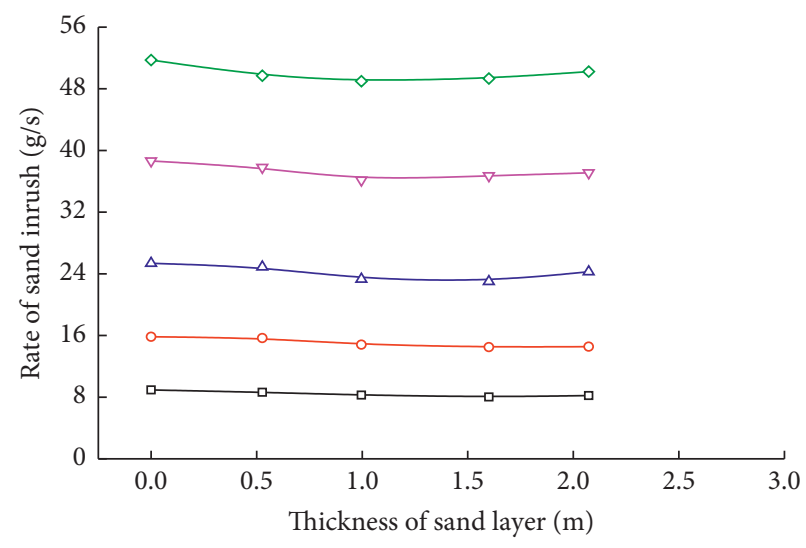

$$
\begin{aligned}
& \multimap-l=2 \mathrm{~mm} \\
& \multimap l=3 \mathrm{~mm} \\
& \multimap l=4 \mathrm{~mm}
\end{aligned}
$$

(b)

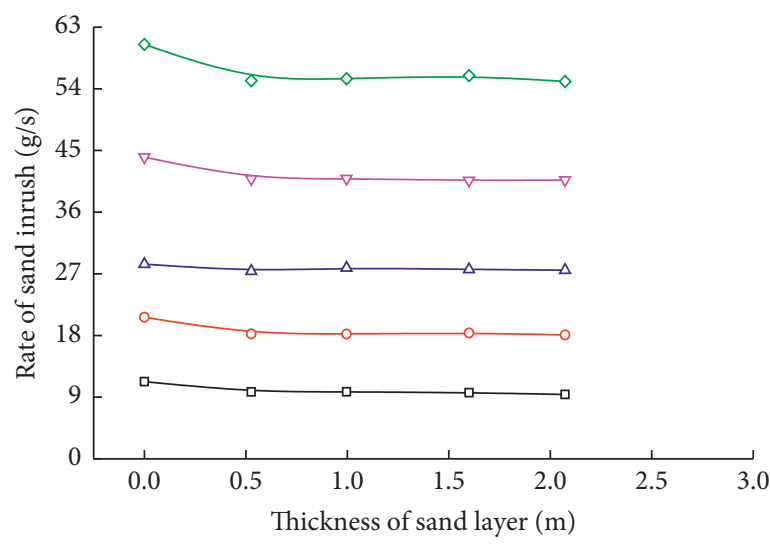

$$
\begin{array}{ll}
\multimap l=2 \mathrm{~mm} & \rightarrow l=5 \mathrm{~mm} \\
\multimap l=3 \mathrm{~mm} & \multimap l=6 \mathrm{~mm} \\
\multimap l=4 \mathrm{~mm} &
\end{array}
$$

(d)

(c)

Figure 8: The influence of sand thickness on fracture sand inrush: (a) $\alpha=45^{\circ}$, (b) $\alpha=55^{\circ}$, (c) $\alpha=65^{\circ}$, and (d) $\alpha=90^{\circ}$. 


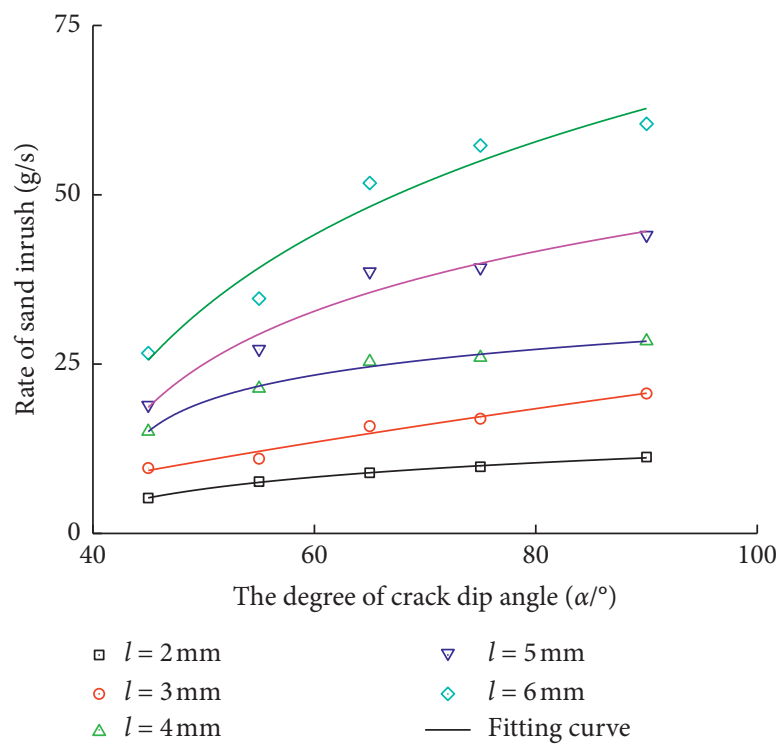

FIGURE 9: The curve of the relationship between the angle of fracture and the velocity of sand inrush.

It can be seen from Figure 8 that when the fracture angle and opening are fixed, the fracture sand inrush has no obvious change in velocity when the overlying sand bed is getting thicker. It can be seen from Figures 8(a) and 8(b) that when the fracture angle is small, the velocity of fracture sand inrush is almost constant when the sand bed is getting thicker. It can be seen from Figures $8(\mathrm{c})$ and $8(\mathrm{~d})$ that when the fracture angle is large, the influence of sand bed thickness on the sand inrush characteristics of fractures with a small opening degree of fracture can be ignored. At the same time, it is not hard to find that when the fracture opening is large, the influence of sand bed thickness on the sand inrush characteristics of fracture specimens with small fracture angle can also be ignored. When both the fracture opening and angle are large, the sand bed thickness has a slight impact on the fracture sand inrush characteristics: with the increase of the sand bed thickness, the velocity of fracture sand inrush slightly decreases rather than increases.

The sand grains used in the test are in a free and loose state. When no weight is applied, the friction between sand grains is small, making sand inrush easier; when the weight is applied, the sand grains are compacted to a certain extent, making sand inrush more difficult. However, the influence of sand bed thickness on the fracture sand inrush characteristics is obvious only in terms of the specimens with larger fracture opening and angle, while the influence on other specimens is negligible or can be ignored. It can be judged from the above that the weight of influence of fracture opening and angle on fracture sand inrush characteristics is far greater than that of sand bed thickness.

From the above analysis, it can be seen that the increase of sand bed thickness can only increase the amount but not the velocity of sand inrush into the fracture.

\subsection{Influence of Fracture Properties on Fracture Sand Inrush} Characteristics. For the fracture specimen used in the test, the angle between the fracture and the horizontal direction has five preset values, namely $90^{\circ}, 65^{\circ}, 55^{\circ}$, and $45^{\circ}$; the fracture opening also has five preset values, namely 2, 3, 4, 5, and $6 \mathrm{~mm}$. Figure 9 shows the influence of fracture angle on sand inrush velocity under different fracture opening. As can be seen in Figure 9, when the fracture opening is fixed, the sand inrush velocity of the fracture tends to increase at a declining rate when the angle between the fracture and the horizontal direction is increasing.

Figure 10 shows the curve of the relationship between sand inrush velocity and fracture opening when the inclination between fracture and the horizontal direction is fixed. It can be seen from the figure that the sand inrush velocity of fracture increases at an accelerating rate when the fracture opening is increasing.

As shown in Figures 9 and 10, when the fracture opening is fixed, the sand inrush velocity of the fracture increases at a declining rate when the angle increases. In theory, the fracture opening can increase infinitely, but the angle of the fracture is limited, which indicates that the influence of fracture opening on fracture sand inrush velocity is greater than that of fracture angle on fracture sand inrush velocity.

Table 2 fits the relationship between the sand break rate and the fracture dip angle in Figure 9. It can be seen from the table that under the condition of certain fracture opening, the sand breaking rate of fracture has a logarithmic relationship with the fracture dip angle. The fitting equation in Table 2 can be as follows:

$$
v_{m}=A-B \ln (\alpha+C),
$$

where $v_{m}$ means the mass of sand grains that break out every second; $\alpha$ means Crack dip angle; $\mathrm{A}, \mathrm{B}$, and $\mathrm{C}$ are fitting coefficients.

Through simultaneous analysis of the fracture opening $l$ in Table 1 and coefficient in the fitting equation, as shown in Table 3, it can be seen that all the three parameters have a certain functional relationship with the inclination of the fracture, as shown in Figure 11. It can be concluded that

The fitting relationship between parameter $\mathrm{A}$ and the fracture opening is as follows: 


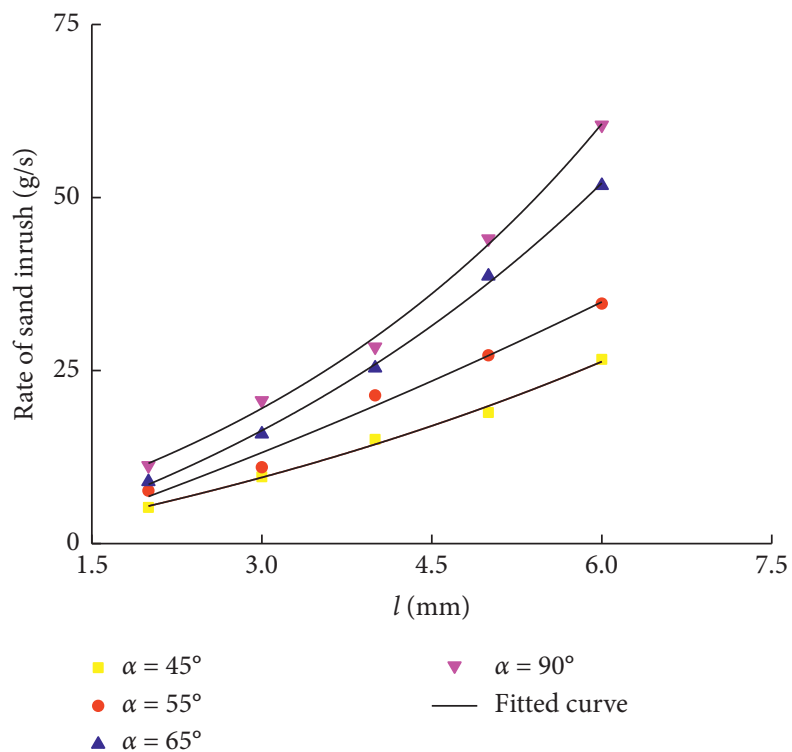

FIgURE 10: The curve of the relationship between the opening degree of fracture and the velocity of sand inrush.

TABle 2: Effect of fracture angle on the rate of collapse under different fracture size.

\begin{tabular}{lcc}
\hline Crack opening $l(\mathrm{~mm})$ & Fitting equation of the velocity of sand inrush and the opening degree of fracture & Related coefficients \\
\hline 2 & $v_{m}=-4.46-3.86 \ln (\alpha-35.6)$ & $R^{2}=0.99515$ \\
3 & $v_{m}=6.06-2.67 \ln (\alpha-41.8)$ & $R^{2}=0.93608$ \\
4 & $v_{m}=7.925 .26 \ln (\alpha-41.13)$ & $R^{2}=0.98309$ \\
5 & $v_{m}=-13.69-14.61 \ln (\alpha-35.9)$ & $R^{2}=0.92270$ \\
6 & $v_{m}=-48.28-27.1 \ln (\alpha-29.71)$ & $R^{2}=0.89861$ \\
\hline
\end{tabular}

TABLE 3: Relationship between fracture inclination and fitting parameters.

\begin{tabular}{lccr}
\hline Crack opening $l$ & A & B & C \\
\hline $45^{\circ}$ & -4.46 & -3.86 & -32.59 \\
$55^{\circ}$ & 6.06 & -2.67 & -41.8 \\
$65^{\circ}$ & 7.92 & -5.26 & -41.13 \\
$75^{\circ}$ & -13.69 & -14.61 & -35.87 \\
$90^{\circ}$ & -48.28 & -27.087 & -29.71 \\
\hline
\end{tabular}

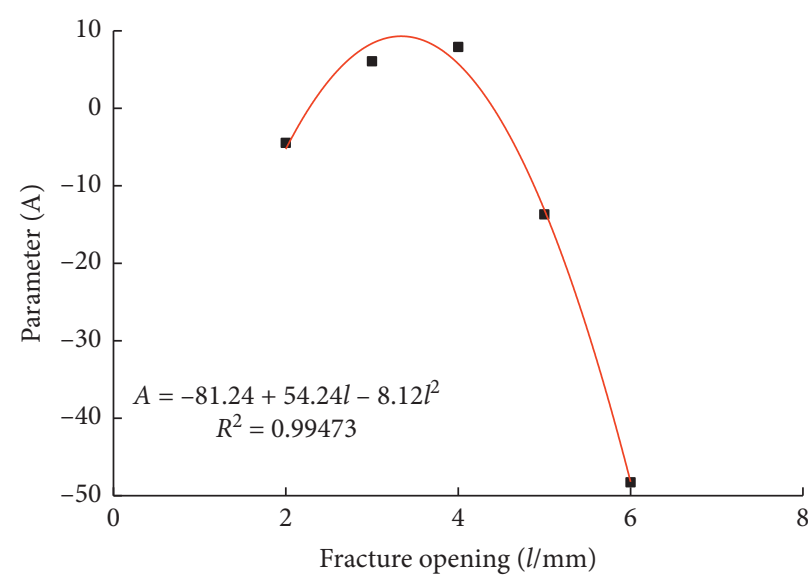

- Parameter point Fitting curve

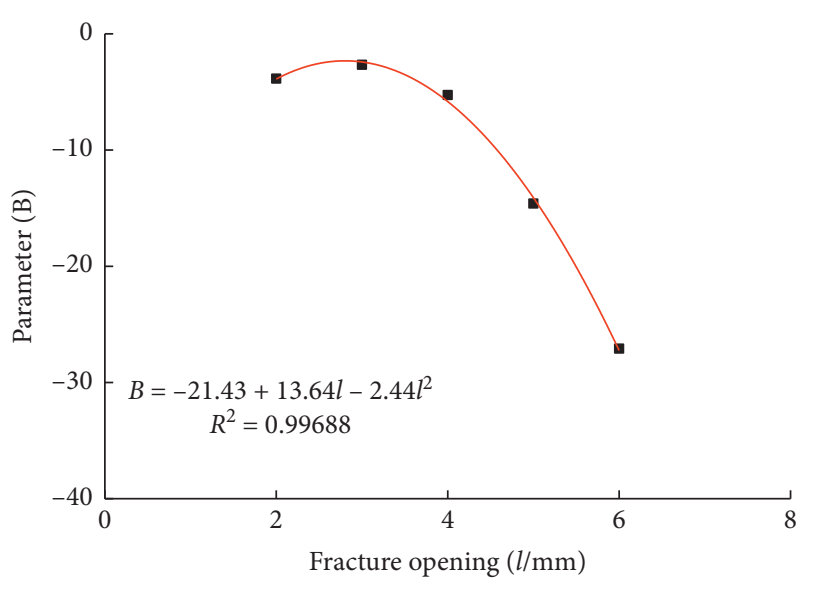

- Parameter point Fitting curve 


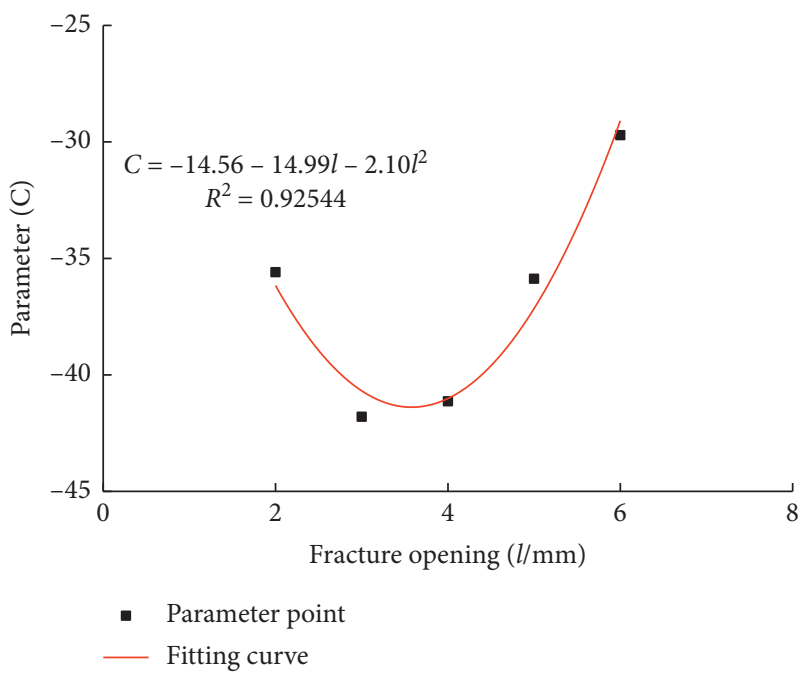

(c)

Figure 11: Curve of the relationship between the level of the fracture and the fitting parameters: (a) Parameter A, (b) Parameter B, and (c) Parameter C.

$$
\begin{aligned}
A & =-81.24+54.24 l-8.12 l^{2}, \\
R^{2} & =0.99473 .
\end{aligned}
$$

The fitting relationship between parameter $\mathrm{B}$ and the fracture opening is as follows:

$$
\begin{aligned}
B & =-21.43+13.64 l-2.44 l^{2}, \\
R^{2} & =0.99688,
\end{aligned}
$$

The fitting relationship between parameter $\mathrm{C}$ and the Fracture opening is as follows:

$$
\begin{aligned}
C & =-14.56-14.99 l+2.10 l^{2}, \\
R^{2} & =0.92544 .
\end{aligned}
$$

Equations (6), (7), (8), and (9) can be used to establish a fracture sand inrush calculation model and to get the sand inrush velocity of any angle and any fracture opening, as shown in equations (10). Equation (10) takes into consideration the inclination and the opening degree of fracture and can reflect the influence of these two factors on the velocity of sand inrush.

$$
\left\{\begin{array}{l}
v_{m}=A-B \ln (\alpha+C), \\
A=-81.24+54.24 l-8.12 l^{2}, \\
B=-21.43+13.64 l-2.44 l^{2}, \\
C=-14.56-14.99 l+2.10 l^{2},
\end{array}\right.
$$

In equation (10), $\alpha$ means the inclination of fracture and $l$ is the opening degree of fracture.

According to equation (10), we have drawn a curved surface diagram of the comprehensive influence of the angle and opening degree of fracture on the velocity of sand inrush, as shown in Figure 12. It can be seen from Figure 12 that the calculation results in equations (10) are in good agreement with the experimental data, which shows that the derived equation is effective.

\section{Study of Fracture Sand Inrush Value Based on Grain Flow}

Particle Flow Code (PFC) series software is a grain flow analysis program developed by Itasca Consulting Group based on the discrete element. Different from continuum mechanical method, PFC software based on grain flow discrete element endows materials with macroproperties by defining the microparameters of grains, while the constitutive relations between materials are realized by the contact constitutive relations of grains.

As there was no stress arch phenomenon in a similar simulation experiment, in order to study this situation and according to the similar test model of fracture sand inrush, the PFC grain flow software was used to build a numerical model, and the wall module in the software used to simulate the fracture channel. Grains were used to represent Aeolian sand, with the grain size of Aeolian sand ranging from $0.00074 \mathrm{~m}$ to $0.00250 \mathrm{~m}$, and the density is $1.8 \times 10^{3} \mathrm{~kg} / \mathrm{m}^{3}$. The parameters such as sand bed thickness, fracture width, and fracture inclination are consistent with the physical test parameters. In the numerical experiment, there was no stress arch in the sand bed but a through fracture which finally turned into a funnel. Due to a large number of test screenshots and limited space, only the numerical calculation results of specimen $6-180$ and specimen $2-180$ is given here in Figure 13.

In order to further study the possible conditions for the occurrence of stress arches, the grain flow was used to simulate the sand inrush in the case of two models with fracture widths of $1.5 \mathrm{~mm}$ and $0.8 \mathrm{~mm}$, respectively. When 


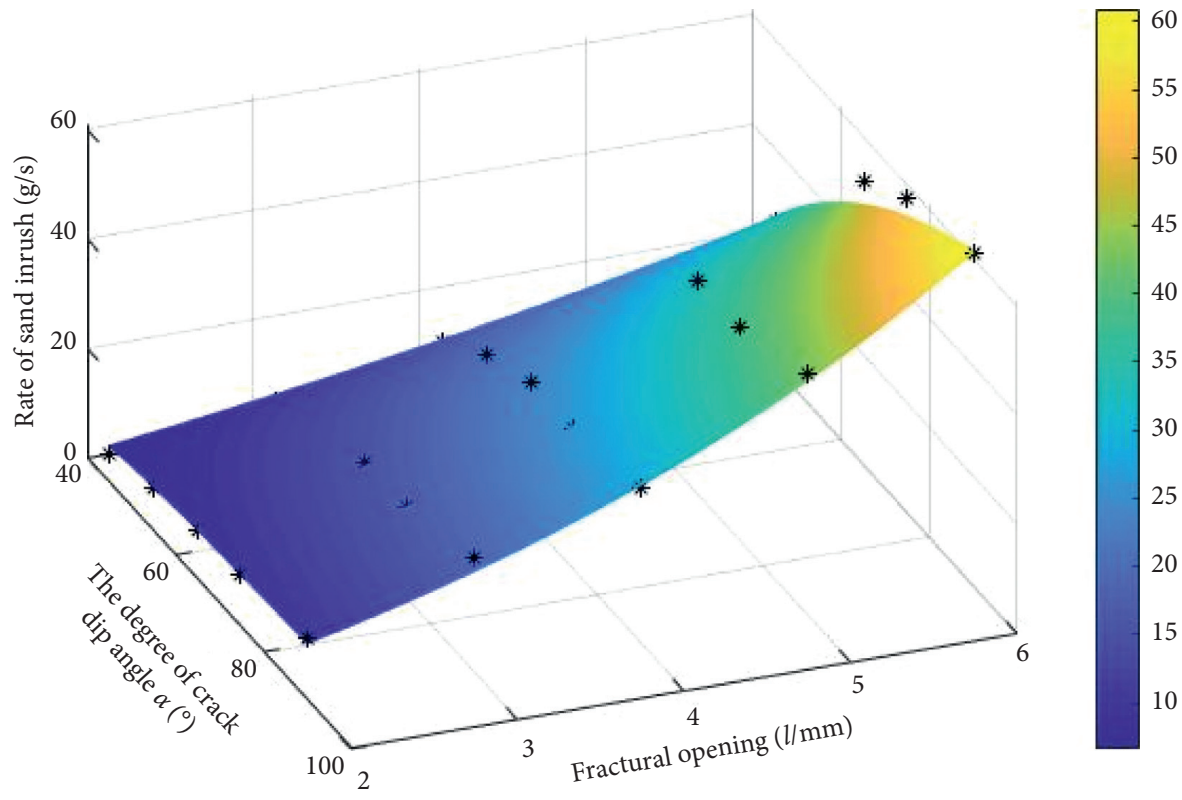

Experimental data

FIGURE 12: Sand inrush velocity distribution diagram considering both opening degree and inclination of fracture.

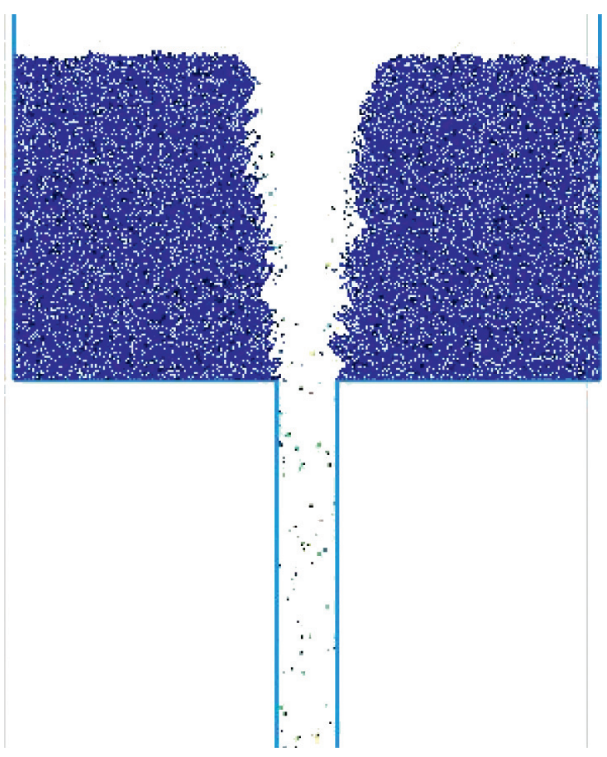

(a)

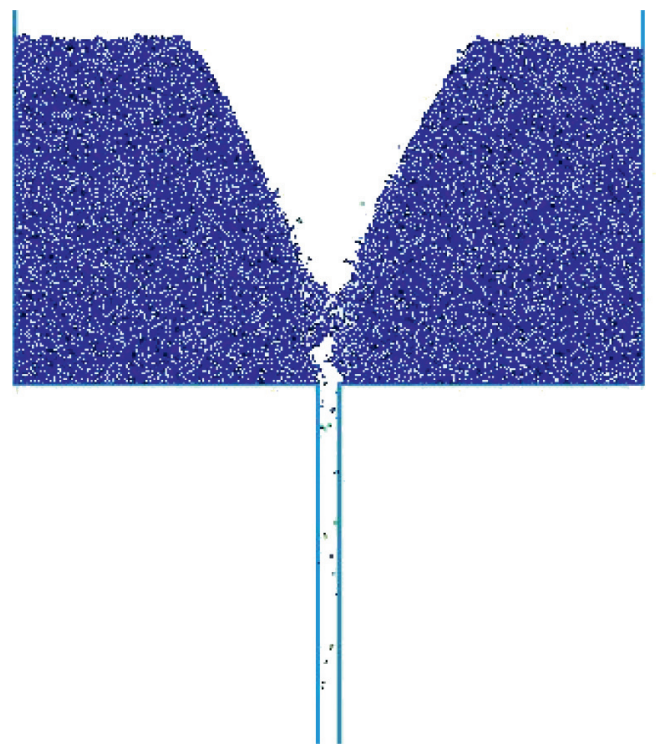

(b)

Figure 13: Sand inrush funnel. (a) Specimen 6-90 and (b) Specimen 2-90.

the fracture width was $1.5 \mathrm{~mm}$, the fracture channel still appeared in the model; when the fracture width is $0.8 \mathrm{~mm}$, a tiny arch was formed as the sand grains could not break out from the fracture due to mutual compression, although the fracture width is still larger than the average diameter of Aeolian sand grains (Figure 14). 


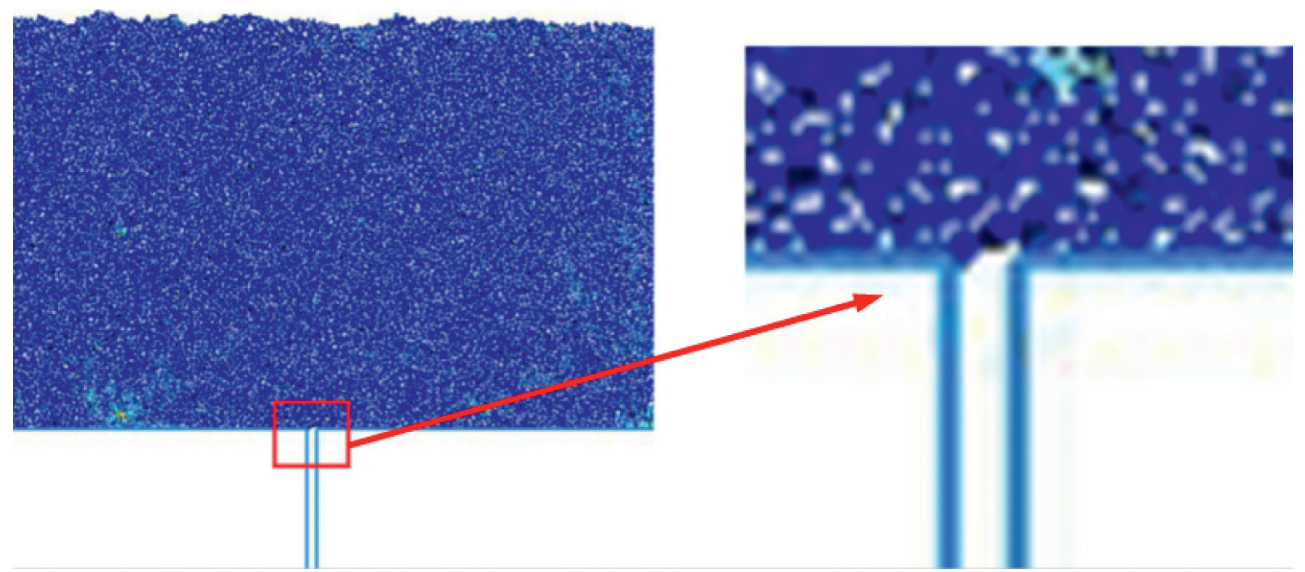

FIGURE 14: Stress arch in 0.8-90 model sand inrush test.

\section{Conclusion}

For the purpose of this paper, the self-developed fracture sand inrush test system was used to study the fracture specimens with different fracture opening and inclination; numerical analysis was carried out based on the discrete element software, revealing the flow characteristics of sand grains in fractures without the use of water and reaching the following conclusions:

(1) The compression method is used to simulate the inrush of sand grains in sand beds of different thicknesses into fractures. Under the same conditions, the thickness of the sand bed has no obvious effect on the velocity of sand inrush. When the fracture has a larger opening degree, the lower part of the thick sand bed is compacted, and the velocity of sand inrush will be slightly reduced. It can be judged from the above that the weight of influence of fracture opening and angle on fracture sand inrush characteristics is far greater than that of sand bed thickness. From the above analysis, it can be seen that the increase of sand bed thickness can only increase the amount but not the velocity of sand inrush into the fracture.

(2) When the opening degree of fracture is fixed, the sand inrush velocity of the fracture tends to increase at a declining rate when the angle between the fracture and the horizontal direction is increasing. Under the same conditions, the angle of fracture has a logarithmic relationship with the velocity of sand inrush. When other conditions remain unchanged, the sand inrush velocity of fracture increases at an accelerating rate when the fracture opening is increasing. The velocity of sand inrush increases at an accelerating rate when the opening degree of fracture is increasing. Therefore, there is an exponential relationship between the opening degree of fracture and the velocity of sand inrush.

(3) Through the fitting of the opening degree of fracture and the velocity of sand inrush, it is found that there is a certain functional relationship between the parameters of the fitting formula and the angle of the fracture. The parameters in the expression of fracture opening and sand inrush velocity are represented by fracture angle, and the formula for calculating sand inrush velocity at any fracture angle and opening degree is provided.

(4) In the fracture sand inrush test, no stress arch occurred because of the larger fracture width (the smallest opening degree of fracture specimen is $2 \mathrm{~mm}$ ) or the limited size of the test instruments. Based on grain flow software, the numerical simulation study of fracture sand inrush is carried out, and the study results are consistent with those of the physical test. When the opening degree of fracture is set at $0.8 \mathrm{~mm}$, the sand grains cannot collapse.

\section{Data Availability}

The data used to support the findings of this study are available from the corresponding author upon request.

\section{Conflicts of Interest}

The authors declare that they have no conflicts of interest.

\section{Acknowledgments}

This work was supported by the National Natural Science Foundation of China (nos. 51904113, 51904112, 51804129, and 51904111), the Natural Science Foundation of Henan Province (202300410170), and the 2019 Huaishang Talent Plan Program. 


\section{References}

[1] W.-Q. Zhang, J.-D. Yuan, Z.-C. Wang et al., “An experimental study on compressive shear seepage laws of mining-induced fractured rock mass," Rock and Soil Mechanics, vol. 38, no. 9, pp. 2473-2479, 2017.

[2] J. Wu, W. Zhou, T. Hong et al., "Research on failure characteristics and zoning control technology of thick soft surrounding rock for deep gob-side entry retaining," Shock and Vibration, vol. 2020, Article ID 6613514, 14 pages, 2020.

[3] P. Yang and F. E. N. G. Wu-lin, "Research on disaster of water inrush and sand inrush in shallow seam of Shenfu Dongsheng mining area," Coal Science and Technology, vol. 30, no. Supp.1, pp. 65-69, 2002.

[4] B. Zhang, G.-M. Zhang, K. Zhang et al., "Water and sands bursting mechanism induced by geological borehole and control measures," Journal of Mining \& Safety Engineering, vol. 32, no. 2, pp. 219-226, 2015.

[5] X.-J. Zhang, Experimental Investigation and Numerical Simulation on Quicksand through Caving Rock Mass Based on Granular Flow theory, China University of Mining and Technology, Xuzhou, China, 2016.

[6] J. Wu, Y. Dong, J. Chen et al., "Short cantilever rock beam structure and mechanism of gob-side entry retaining roof in reuse period," Shock and Vibration, vol. 2020, Article ID 8864991, 14 pages, 2020.

[7] L. Bian, L. Wang, and C.-P. Liu, "Constitutive relation of pseudo-fluid granular flow," The Chinese Journal of Process Engineering, vol. 7, no. 3, pp. 467-471, 2007.

[8] G.-Q. Wang and N. I. Jing-Ren, "Review of particle flow research," Mechanics in Engineering, vol. 14, no. 1, pp. 7-19, 1992.

[9] L. I. U. Ming-xiao, X.-H. Zhang, S.-M. Tian et al., "Reviews and prospects of the research on bed load transport," Port \& Waterway Engineering, vol. 42, no. 5, pp. 26-34, 2013.

[10] R. A. Bagnold, "The movement of Desert sand," The Geographical Journal, vol. 85, no. 4, pp. 342-365, 1935.

[11] R. A. Bagnold, An Approach to the Sediment Transport Problem from General physics, U. S. A: US Geological Survey Professional Paper, Washington, DC, USA, 1966.

[12] Y. Song, P. G. Ranjith, and B. Wu, "Development and experimental validation of a computational fluid dynamicsdiscrete element method sand production model," Journal of Natural Gas Science and Engineering, vol. 73, Article ID 103052, 2020.

[13] W.-L. Shen, J.-B. Bai, W.-F. Li, and X.-Y. Wang, "Prediction of relative displacement for entry roof with weak plane under the effect of mining abutment stress," Tunnelling and Underground Space Technology, vol. 71, pp. 309-317, 2018.

[14] Z. Z. Cao, P. Xu, Z. H. Li, M. X. Zhang, Y. Zhao, and W. L. Shen, "Joint bearing mechanism of coal pillar and backfilling body in roadway backfilling mining technology," CMC-computers Materials \& Continua, vol. 54, no. 2, pp. 137-159, 2018.

[15] C. Ancey and J. Heyman, "A microstructural approach to bed load transport: mean behaviour and fluctuations of particle transport rates," Journal of Fluid Mechanics, vol. 744, pp. 129-168, 2014.

[16] T. A. N. G. Li-mo and W. A. N. G. Xing-kui, "Statistical analysis on motion characteristics of satiating particles," Journal of Hohai University (Natural Sciences), vol. 37, no. 2, pp. 232-235, 2009.

[17] K. P. Hadeler and C. Kuttler, "Dynamical models for granular matter," Granular Matter, vol. 2, no. 1, pp. 9-18, 1999.
[18] Q. Sun, G. Wang, and K. Hu, "Some open problems in granular matter mechanics," Progress in Natural Science, vol. 19, no. 5, pp. 523-529, 2009.

[19] J. I. N. De-wu, Y.-F. Liu, Z.-B. Liu et al., "New progress of study on major water inrush disaster prevention and control technology in coal mine," Coal Science and Technology, vol. 41, no. 1, pp. 25-29, 2013.

[20] H. Li, B. A. I. Hai-Bo, J.-J. Wu et al., "Study of evolution process of water-conducting zone in complete floor under cyclic loading," Rock and Soil Mechanics, vol. 38, no. Supp.1, pp. 447-454, 2017.

[21] M. Xie-xing, R.-h. Chen, and B. A. I. Hai-Bo, "Fundamental concepts and mechanical analysis of water-resisting key strata in water-preserved mining," Journal of China Coal Society, vol. 32, no. 6, pp. 561-564, 2007.

[22] L.-M. Fan, M. A. Xiong-de, H. Jiang et al., "Risk evaluation on water and sand inrush in ecologically fragile coal mine," Journal of China Coal Society, vol. 41, no. 3, pp. 531-536, 2016. 